\title{
Corrigendum to "Expression of Intratumoral IGF-II Is Regulated by the Gene Imprinting Status in Triple Negative Breast Cancer from Vietnamese Patients"
}

\author{
Vinodh Kumar Radhakrishnan, Lorraine Christine Hernandez, Kendra Anderson, \\ Qianwei Tan, Marino De León, and Daisy D. De León $\mathbb{D}$
}

Center for Health Disparities and Molecular Medicine, School of Medicine, Loma Linda University, Loma Linda, CA 92350, USA

Correspondence should be addressed to Daisy D. De León; ddeleon@llu.edu

Received 1 August 2018; Accepted 3 August 2018; Published 23 October 2018

Copyright (C) 2018 Vinodh Kumar Radhakrishnan et al. This is an open access article distributed under the Creative Commons Attribution License, which permits unrestricted use, distribution, and reproduction in any medium, provided the original work is properly cited.

In the article titled "Expression of Intratumoral IGF-II Is Regulated by the Gene Imprinting Status in Triple Negative Breast Cancer from Vietnamese Patients" [1], there were errors in Figures 2 and 4. There was lane duplication and undeclared splicing in Figure 2, where the bands used for the sample $11 \mathrm{M}(\mathrm{BA}), 12 \mathrm{~N}(\mathrm{BA})$ were duplicated as lanes $21 \mathrm{M}(\mathrm{BA}), 22 \mathrm{~N}(\mathrm{BA})$ and the lanes for $15 \mathrm{M}(\mathrm{BA}), 16 \mathrm{~N}(\mathrm{BA})$ were triplicated as lanes $17 \mathrm{M}(\mathrm{BA}), 18 \mathrm{~N}(\mathrm{BA})$ and $39 \mathrm{M}(\mathrm{BA})$, $40 \mathrm{~N}(\mathrm{BA})$. There was duplication in Figure 4, where the Ponceau bands in the right-hand panel of Figure 4(a) were rotated 180 degrees in the right-hand panel of Figure 4(c).

The authors asked to correct the article following an institutional investigation, which concluded that these errors were the result of inadvertent human error while cropping and naming the gels and do not affect the conclusions of the article. The labeled scanned data generated from the Gel Doc system are available as Supplementary Materials (available here). In addition, the authors confirmed that the description of the asterisk symbol "*" should be added to the legend of Figure 2. The corrected Figures 2 and 4 are shown below. 

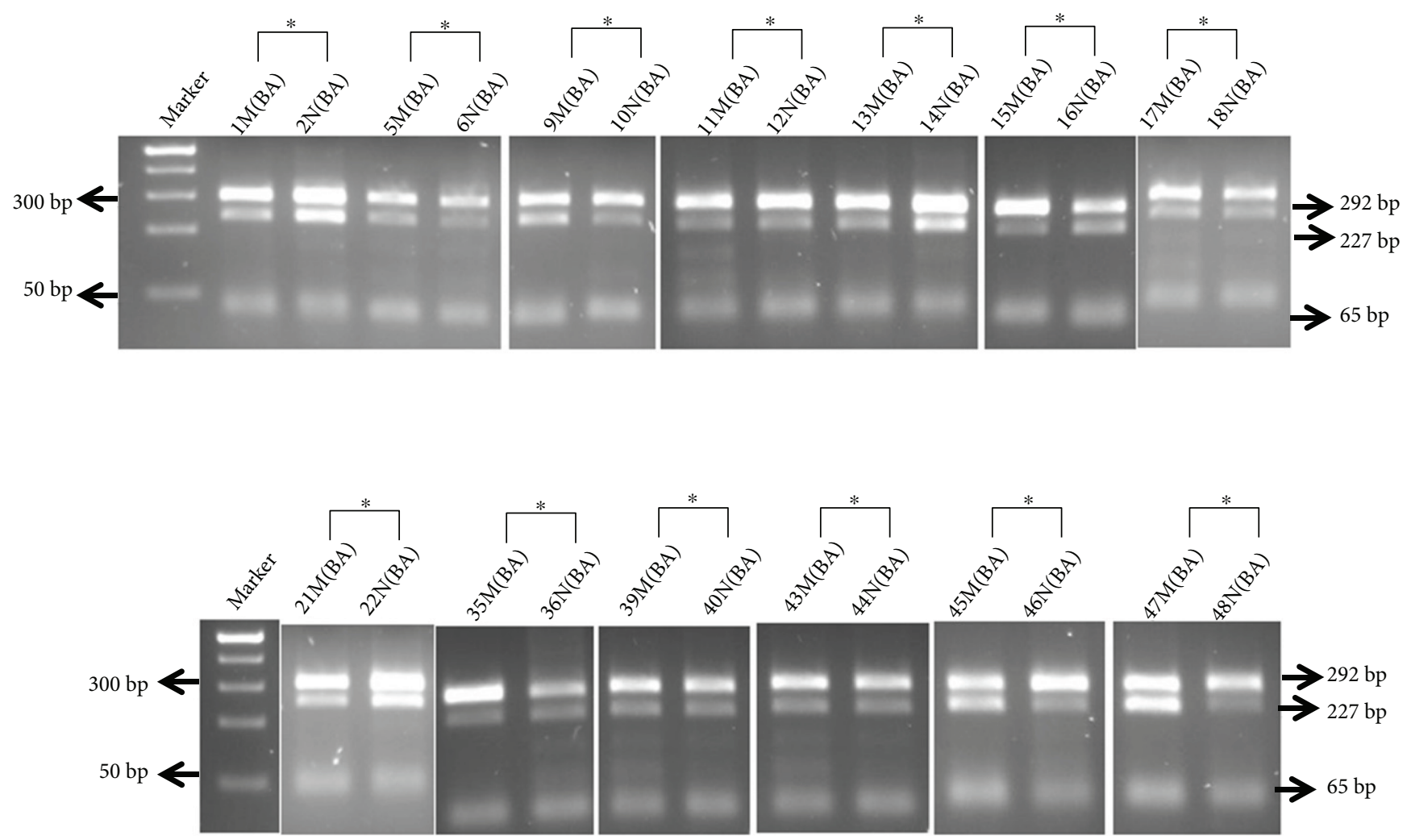

FIgURe 2: ApaI digestion of the $292 \mathrm{bp}$ nested PCR (QPCR) fragment generated from the fragment of 1.12 RT-PCR reactions. Biallelic expression was identifiable by the presence of each of the 292, 227, and $63 \mathrm{bp}$ restriction fragments. The first lane shows Fisher's exACTGene 100 bp DNA Ladder, showing the 500 bp-25 bp respective molecular weight size markers. * denotes paired breast samples from the same patient (normal, malignant). 

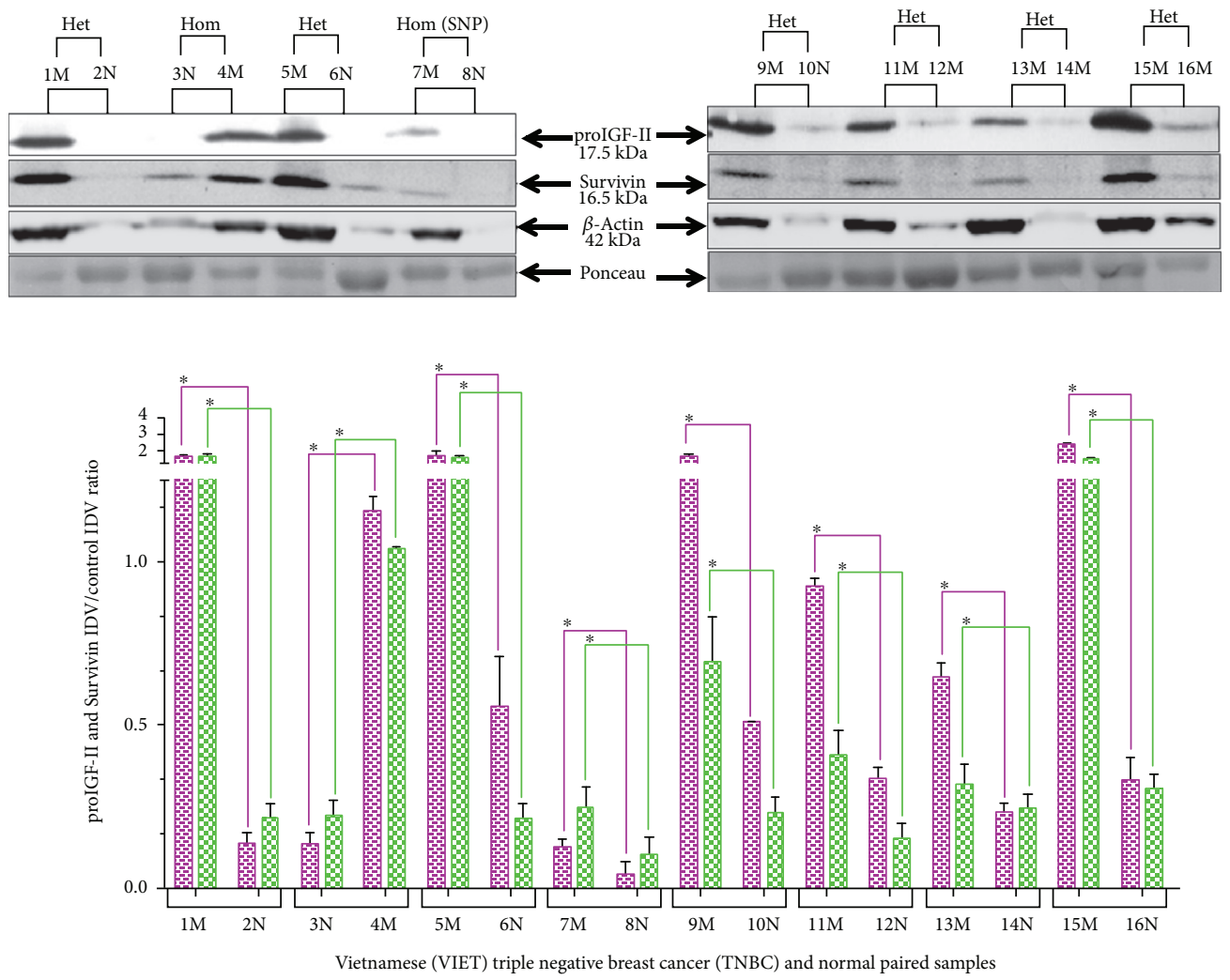

proIGF-II

Wurvivin

(a)
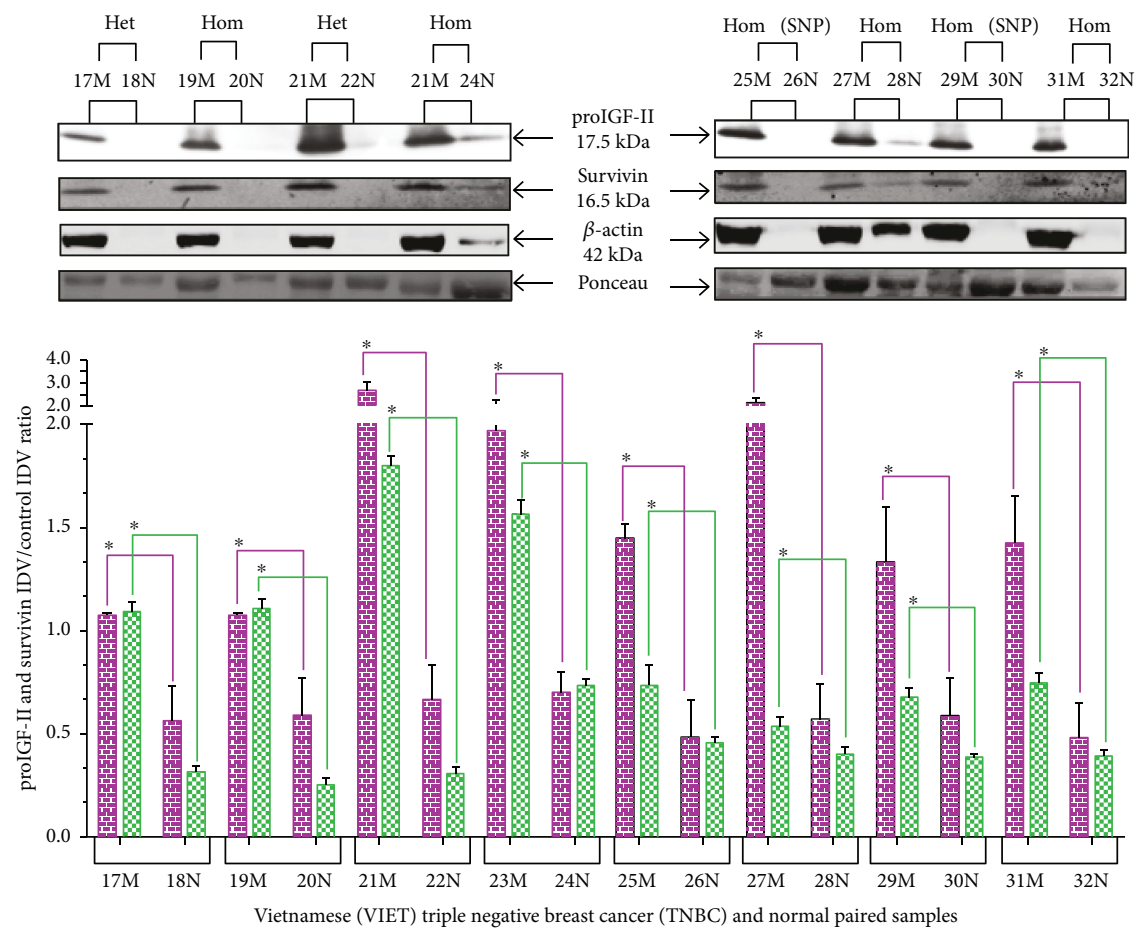

도오 proIGF-II

맘 Survivin

(b)

Figure 4: Continued. 

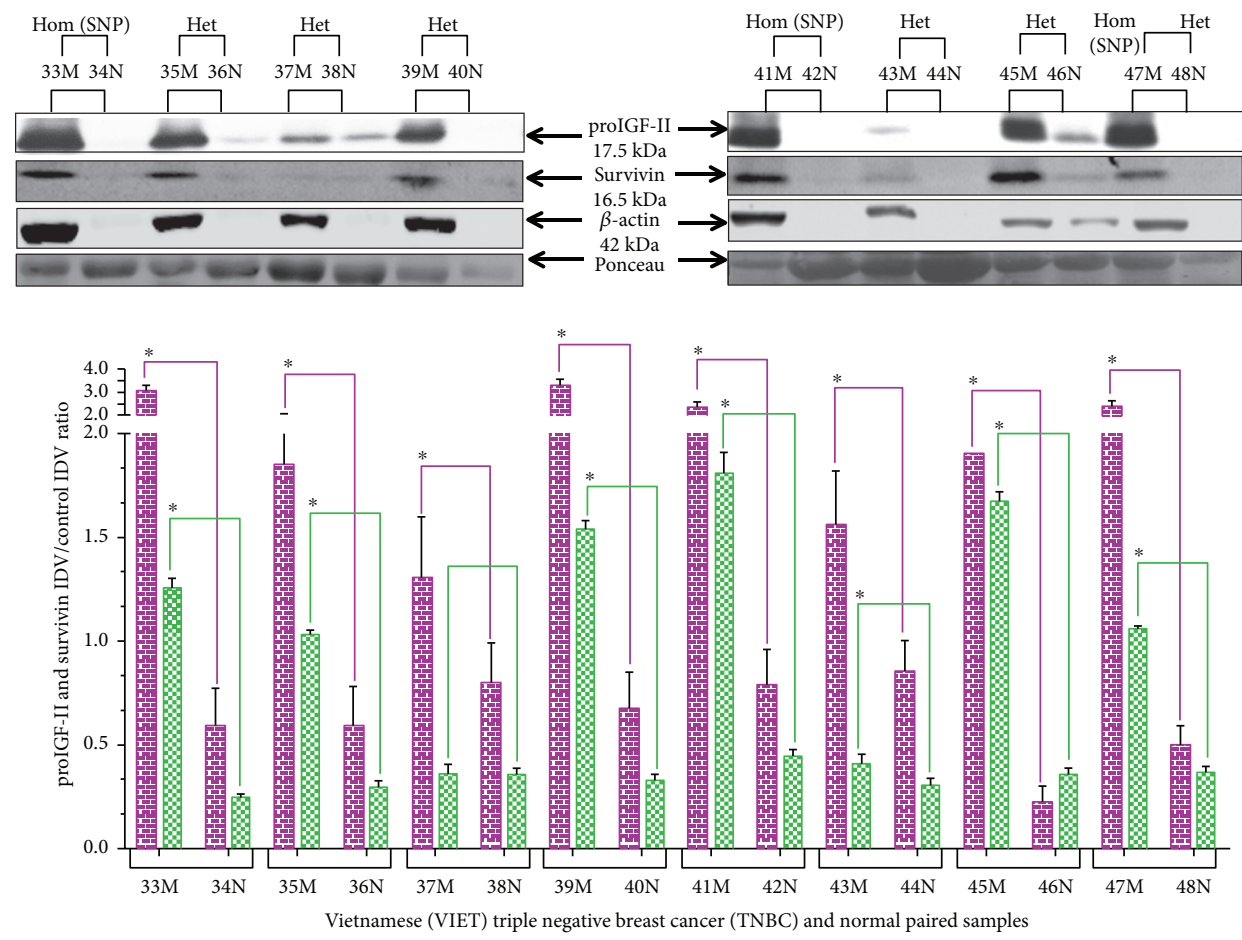

proIGF-II

Survivin

(c)

FIgURE 4: ((a), (b), and (c)) Western blot of paired normal/malignant TNBC samples (1-48). The total number of samples $(n)$ analyzed per group was as follows: Heterozygous (Het; $n=27)$, Homozygous with SNP (Hom SNP; $n=11$ ), and Homozygous (Hom; $n=10)$. Bar graphs $(\mathrm{a}-\mathrm{c})$ of free proIGF-II $(17.5 \mathrm{kDa})$ and Survivin $(16.5 \mathrm{kDa})$. Ponceau red staining was used to normalize for sample loading. Bars represent the mean \pm SE of all normalized samples per group. Asterisks indicate values statistically significant $*(p<0.05)$ using the Wilcoxon paired $t$-test.

\section{Supplementary Materials}

Supplementary Materials: the labeled scanned data generated from the Gel Doc system. (Supplementary Material)

\section{References}

[1] V. K. Radhakrishnan, L. C. Hernandez, K. Anderson, Q. Tan, M. De León, and D. D. De León, "Expression of intratumoral IGF-II is regulated by the gene imprinting status in triple negative breast cancer from Vietnamese patients," International Journal of Endocrinology, vol. 2015, Article ID 401851, 13 pages, 2015. 


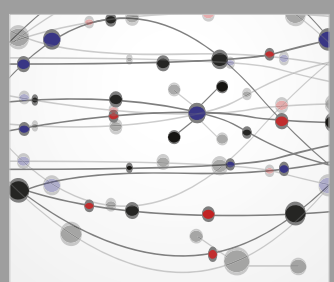

The Scientific World Journal
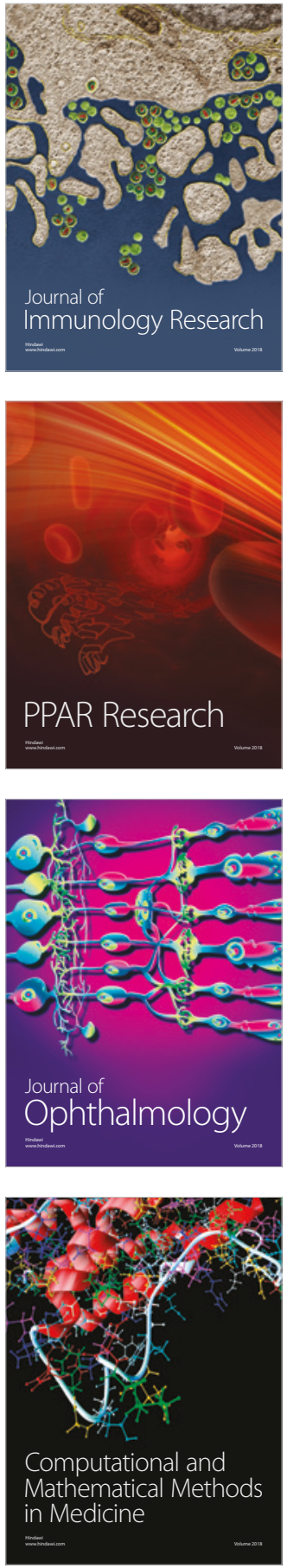

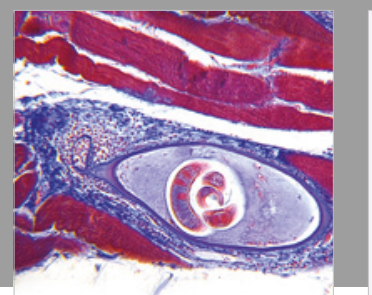

Gastroenterology Research and Practice

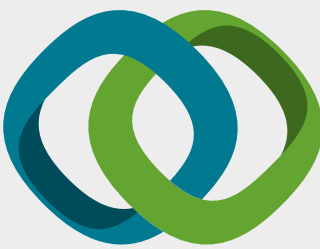

\section{Hindawi}

Submit your manuscripts at

www.hindawi.com
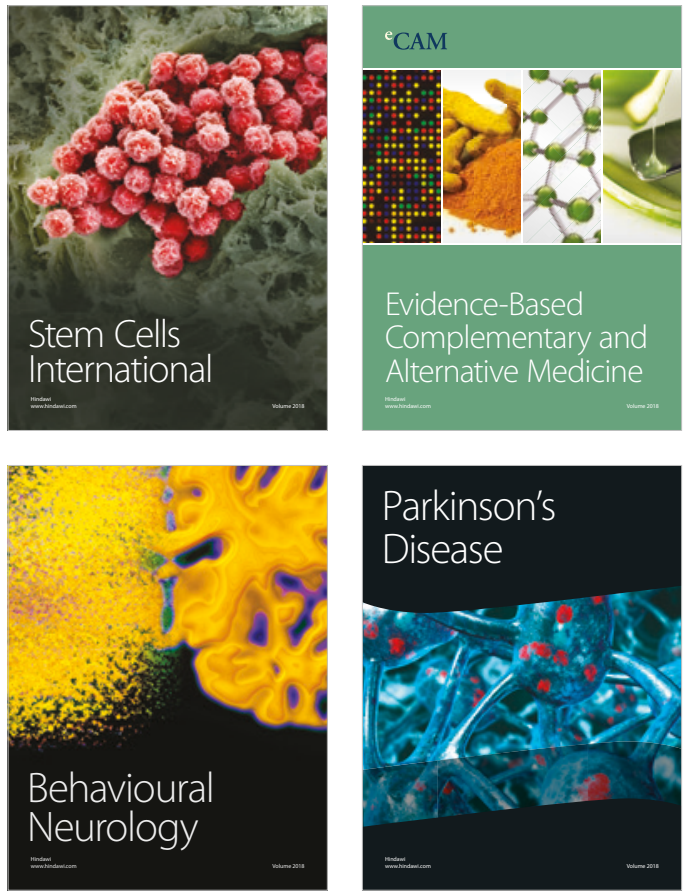

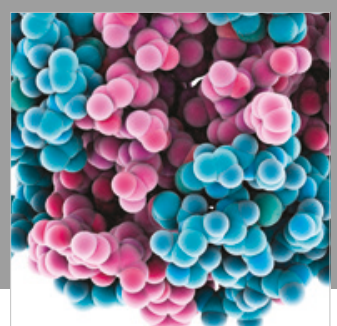

ournal of

Diabetes Research

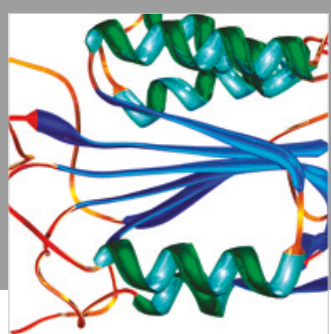

Disease Markers
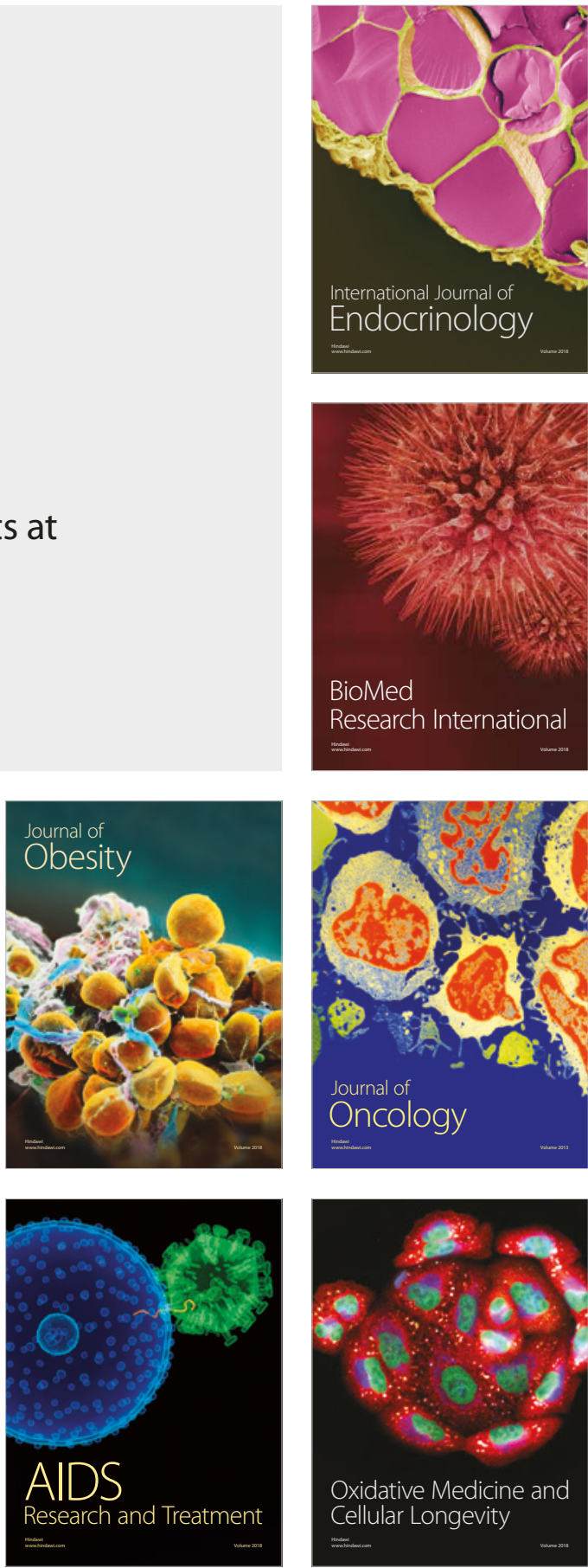